\title{
Preparation and Delayed Release Study on Pancreatin Encapsulated into Alginate, Carrageenan and Pectin Hydrogels
}

\author{
Fernanda M. P. Olímpio, ${ }^{\dagger, a}$ Adriano A. Mendes, ${ }^{b}$ Marcello G. Trevisan ${ }^{\circledR *, a}$ and \\ Jerusa S. Garcia ${ }^{a}$ \\ ${ }^{a}$ Laboratório de Análises e Caracterização de Fármacos (LACFar), Instituto de Química, \\ Universidade Federal de Alfenas, 37130-001 Alfenas-MG, Brazil \\ ${ }^{b}$ Instituto de Química, Universidade Federal de Alfenas, 37130-001 Alfenas-MG, Brazil
}

\begin{abstract}
In this study, biopolymer-based $\mathrm{pH}$-sensitive hydrogels have been successfully prepared using alginate, $\kappa$-carrageenan and pectin aimed at the encapsulation of pancreatin (hydrolytic enzymes like $\alpha$-amylase, lipase and protease) so as to preserve enzymatic activities. Hydrogels have been characterized by Fourier transform infrared spectroscopy (FTIR), thermogravimetric analysis (TGA), scanning electron microscopy (SEM), swelling degree and swelling profile. Encapsulation efficiency and in vitro studies on delayed release have also been evaluated. All hydrogels presented low swelling degree and enzyme release in a gastric medium. On the other hand, high swelling degree and enzyme release were observed in an intestinal medium. Alginate hydrogel achieved optimal results concerning encapsulation efficiency (18, 68 and 53\% for $\alpha$-amylase, lipase and protease, respectively) and delayed release (363, 7,673 and 17,497 $\mathrm{U}$ for $\alpha$-amylase, lipase and protease, respectively) which has been afterwards compared to a commercial pancreatin formulation $\left(\right.$ Creon $\left.^{\mathrm{TM}} 10,000\right)$. Thus, it presented better performance than its commercial formulation, mainly in respect of lipase.
\end{abstract}

Keywords: biopolymers, structural characterization, $\alpha$-amylase, lipase, protease, delayed release studies

\section{Introduction}

Deficiency in digestive enzymes secretion can cause malnutrition problems, chronic pancreatitis and cystic fibrosis. ${ }^{1}$ Pancreatic enzyme replacement therapy has been successfully used in the treatment of pancreatic insufficiency due to being highly safe and having few side effects. ${ }^{2}$ Pancreatin is a complex mixture of enzymes from porcine pancreas, including $\alpha$-amylases, lipases and proteases (chymotrypsin and trypsin), which are involved in the digestion of carbohydrates, triacyclglycerols (oils and fats) and proteins, respectively. ${ }^{3}$ However, some drawbacks have been reported on the oral administration of pancreatin, including enzyme destruction in the stomach, lack of adequate mixing with chyme in the duodenum, thus ending in failure at delivering and activating at appropriate time. In this context, promising strategies have been proposed to stabilize their catalytic activity from acids and proteases in the gastrointestinal tract, not only to improve

*e-mail: mgtrevisan@gmail.com

${ }^{\dagger}$ In memoriam the efficiency of action in the duodenum, but to develop better means for monitoring therapies. ${ }^{2}$ These strategies consist in a chemical modification of proteins, application of formulation vehicles, enzyme inhibitors, absorption enhancers and mucoadhesive polymers. Among them, formulation vehicles employing cytocompatible materials have been widely used to incorporate bioactive agents, including therapeutic proteins. ${ }^{3}$

Delayed release is a drug delivery system based on using a vehicle and a drug, i.e., biopharmaceutical, which must be released at a specific location by means of micro (or nano) capsules formed by polymeric matrices to stabilize formulations. ${ }^{4}$ Encapsulation has been widely employed in therapeutic protein stabilization due to increasing stability and reducing inactivation, either by means of structural distortions, modifications in $\mathrm{pH}$ and temperature per covalent attachments or ionotropic gelation. ${ }^{5,6}$ Encapsulation by ionotropic gelation has been successfully employed to prepare hydrogels with sodium alginate, $\kappa$-carrageenan and pectin, ergo natural anionic polymers have been selected for this study due to 
their biodegradability, low cost and mainly non-toxicity to human organisms. ${ }^{6,7}$ These hydrogels are hydrophilic colloids which are capable of forming three-dimensional polymeric structures, also known as intelligent systems, since they exhibit behavioral modifications when subjected to $\mathrm{pH}$ variation (e.g., acid conditions in gastric fluid and near-neutral conditions in the intestine) and/or temperature alteration. These characteristics have caught the attention of pharmaceutical industries aimed at developing a delayed release of therapeutic agents (such as protein and enzymes). ${ }^{5-9}$

Alginate polysaccharide is a linear block copolymer containing polyanionic blocks (mannuronic and guluronic acid blocks) obtained from brown seaweed extracts, which has the ability to form strong hydrogels with divalent ions due to the electrostatic attraction between cations and polymeric molecules driven by carboxyl groups. Alginate has been successfully employed for embedding and transporting therapeutic agents. ${ }^{7}$ Pectin, commonly found in citrus, is constituted of a highly complex and heterogeneous group of polysaccharides that possess a backbone consisting of a linear chain of (1-4)- $\alpha$-D-galacturonic acid. A large number of side chains (composed of over 20 kinds of neutral sugars) are often attached to the backbone chain. Carboxylic groups can be partially esterified with the methyl group, thus resulting in different esterification degrees such as high methoxylation (above $50 \%$ of esterification pectin is less soluble) and low methoxylation (below $50 \%$, pectin is more soluble). ${ }^{10}$ Pectin can also be crosslinked to divalent cations and form hydrogels by following the so-called egg-box model. Carrageenan is a linear polysaccharide obtained commercially by its extraction from certain species of red seaweeds. They are linear polysaccharides composed of D-galactose and 3,6-anhydrogalactose units with varying degree of sulfonation. $\kappa$-Carrageenan has an ester sulfate group on position 4 of the galactose unit. It is reported that it is primarily bound with potassium to form hydrogels. ${ }^{5}$

Zhang et $a l .{ }^{3}$ used an alginate hydrogel to encapsulate only pancreatic lipase. However, the authors focused their efforts to map the $\mathrm{pH}$ microclimate inside hydrogel beads (fabricated with magnesium hydroxide employed as buffer) under simulated gastrointestinal conditions. Moreover, it is worth mentioning that the gelling agent and cross linker concentrations were different, thence resulting in distinct properties of hydrogel beads.

Three enzymes have been simultaneously encapsulated into different materials in the present study in order to develop biopolymer-based $\mathrm{pH}$-sensitive hydrogels able to protect pancreatin enzymes ( $\alpha$-amylase, lipase and protease) from a simulated gastric fluid, besides promoting delayed release of digestive enzymes in a simulated intestine fluid with high catalytic activity. These hydrogels could provide an alternative treatment to patients who have been undergoing this type of therapy. In this study, a comparison of three prepared hydrogels and a commercially available pancreatin formulation $\left(\right.$ Creon $\left.^{\mathrm{TM}} 10,000\right)$ has also been made so as to verify their capacity to preserve enzymatic activities of $\alpha$-amylase, lipase and protease. The commercial formulation consists of coatedminimicrospheres with several excipients. Hence, the use of hydrogels allowed a drastic reduction in the amount of excipients used in the formulation and, consequently, their influence on enzymatic release.

\section{Experimental}

\section{Chemicals}

Pancreatin 8xUSP (P7545) was acquired at SigmaAldrich Co. (St. Louis, MO, USA). It is a powder enzyme composed of $\alpha$-amylase, lipase and protease whose activities are 200, 16 and $200 \mathrm{U}$, respectively, per $\mathrm{mg}$ of material (technical information from Sigma-Aldrich). Alginic acid sodium salt (120,000-190,000 $\mathrm{g} \mathrm{mol}^{-1}$ and ratio of mannuronic acid to guluronic acid of 1.56), $\kappa$-carrageenan and pectin $\left(60,000-90,000 \mathrm{~g} \mathrm{~mol}^{-1}\right.$ and $30 \%$ methylation degree) were purchased from Sigma-Aldrich, Walmon Commercial (São Paulo, SP, Brazil) and CPKelco (Limeira SP, Brazil), respectively. Creon ${ }^{\mathrm{TM}} 10,000$ (10,000 U lipase; 33,200 U $\alpha$-amylase and 37,500 U protease) was acquired at Abbott Laboratories GmbH (São Paulo, SP, Brazil). This commercial formulation contains not only enzymes, but excipients such as macrogol, hypromellose phthalate, cetyl alcohol, triethyl citrate, dimethicone, gelatin, anhydrous iron oxide (III), hydrated iron oxide (III), iron oxide (II, III), titanium dioxide and sodium lauryl sulfate (technical information from Abbott Laboratories $\mathrm{GmbH}$ ). Azocasein and trichloroacetic acid were obtained from Sigma-Aldrich, starch from Synth $^{\text {TM }}$ (São Paulo, SP, Brazil) and olive oil (low acidity, Carbonell) from a local market (Alfenas, MG, Brazil). All other reagents were of analytical grade from Synth $^{\mathrm{TM}}$ and Vetec Química (São Paulo, SP, Brazil).

\section{Encapsulation procedure}

In this study, biopolymer-based $\mathrm{pH}$-sensitive hydrogels have been prepared according to previous studies ${ }^{6,11}$ with slight modifications. At first, polymeric solutions were prepared by dissolving sodium alginate or pectin $\left(6 \%, \mathrm{~m} \mathrm{v}^{-1}\right)$ and $\kappa$-carrageenan $\left(3.5 \%, \mathrm{~m} \mathrm{v}^{-1}\right)$ in $25 \mathrm{~mL}$ of $50 \mathrm{mmol} \mathrm{L}^{-1}$ Tris-HCl buffer at $\mathrm{pH} 7.5$. The solutions were then placed in a glycerin bath at $60^{\circ} \mathrm{C}$ under mechanical agitation to promote 
a complete solubilization of each biopolymer, followed by cooling alginate and pectin solutions until reaching room temperature $\left(25^{\circ} \mathrm{C}\right)$ and up to $40^{\circ} \mathrm{C}$ for the $\kappa$-carrageenan solution. A pancreatin solution $(25 \mathrm{~mL})$ containing $0.5 \mathrm{~g}$ of powder was also prepared in $50 \mathrm{mmol} \mathrm{L}^{-1}$ Tris- $\mathrm{HCl}$ buffer at $\mathrm{pH} 7.5$, which has been vortexed for $10 \mathrm{~min}$ and centrifuged for $30 \mathrm{~min}$ at $4000 \mathrm{rpm}$ so as to remove suspended particles. After homogenizing polymeric and enzymatic solutions (volume ratio 1:1), beads were prepared by dropping a mixed solution using a syringe in a $0.75 \%\left(\mathrm{~m} \mathrm{v}^{-1}\right)$ calcium chloride solution $(50 \mathrm{~mL})$ for alginate or pectin and $4.5 \%\left(\mathrm{~m} \mathrm{v}^{-1}\right)$ potassium chloride solution $(50 \mathrm{~mL})$ for $\kappa$-carrageenan. The resultant beads containing encapsulated pancreatin have been cured for 30 min under mechanical agitation. The beads were collected by filtration under vacuum in a Buchner funnel, washed with a respective saline solution to remove residual ions from their external surfaces and stored at $4{ }^{\circ} \mathrm{C}$ until reaching constant mass to air-dry the hydrogel employed in all the other experiments. The hydrogels without enzymatic solution, namely control hydrogel, were also obtained through the same conditions described above, except that the enzymatic solution was replaced by $50 \mathrm{mmol} \mathrm{L}^{-1}$ Tris- $\mathrm{HCl}$ buffer at $\mathrm{pH} 7.5$. These assays were performed in triplicate.

\section{Characterization studies}

\section{Thermogravimetric analysis (TGA)}

A TGA has been performed using a thermobalance (model TGA/DTA7300, SII Nano Technology, Japan) based on Martins et al..$^{12}$ Approximately $3 \mathrm{mg}$ of samples (control and loaded hydrogels) were placed in an aluminum pan and heated at a constant rate of $10{ }^{\circ} \mathrm{C} \mathrm{min}-1$ from 30 to $500{ }^{\circ} \mathrm{C}$ under a nitrogen atmosphere.

\section{Fourier transform infrared spectroscopy (FTIR)}

Spectra were obtained through the FTIR spectroscopy technique with attenuated total reflectance (ATR-FTIR). They were recorded on an infrared spectrometer Nicolet iS50 FTIR (ThermoScientic, USA) coupled with a Pike Gladi ATR Technologies using 64 scans at resolution of $4 \mathrm{~cm}^{-1}$ ranging from 4,000 and $400 \mathrm{~cm}^{-1} .^{12}$

\section{Scanning electron microscopy (SEM)}

SEM images were obtained using a TM3000 Hitachi Analytical Table Top microscope (Tarrytown, NY, USA) at $15 \mathrm{kV}$ of voltage acceleration. Air-dried samples of alginate, $\kappa$-carrageenan and pectin hydrogels loaded with pancreatin and without enzymes were placed in double-sided carbon scotch tape with no pre-treatment to obtain micrographs whose magnification ranged from $50 \times$ to $2,000 \times$. Quantitative analyses of image data were performed using the free software ImageJ version 1.52a developed by Schneider et al. ${ }^{13}$

\section{Swelling degree}

The swelling degree (SD) of hydrogels has been assessed according to a previous study ${ }^{14}$ in which $50 \mathrm{mg}$ of samples had been incubated separately on different media: $10 \mathrm{~mL}$ of simulated gastric fluid (SGF: $100 \mathrm{mmol} \mathrm{L}^{-1}$ $\mathrm{HCl}$ solution $\mathrm{pH} 1.2), 10 \mathrm{~mL}$ of simulated intestinal fluid (SIF: $100 \mathrm{mmol} \mathrm{L}^{-1}$ sodium phosphate buffer $\mathrm{pH}$ 5.5) and distilled water ( $\mathrm{pH}$ 7.0). It was obtained by considering the relative gain of mass in comparison with its initial mass due to incubation at $37^{\circ} \mathrm{C}$ for $2 \mathrm{~h}$ under agitation using an orbital shaker (200 rpm) (equation 1). Excessive medium has been carefully removed from the external surface of hydrogels using absorbent paper. All tests were performed in triplicate.

$\mathrm{SD}(\%)=\left(\frac{\mathrm{W}_{\mathrm{t}}-\mathrm{W}_{0}}{\mathrm{~W}_{0}}\right) \times 100$

where $\mathrm{W}_{\mathrm{t}}$ and $\mathrm{W}_{0}$ are the mass $(\mathrm{mg})$ of hydrogels at $2 \mathrm{~h}$ of incubation and initial time of swelling, respectively.

\section{Swelling profile}

In order to evaluate the swelling profile, $50 \mathrm{mg}$ of each loaded hydrogel were placed in $10 \mathrm{~mL}$ of SGF and incubated at $37^{\circ} \mathrm{C}$ in an orbital shaker under agitation (200 rpm). ${ }^{15}$ At 15, 30, 60, 90 and 120 min, hydrogels were collected to determine their masses. After $2 \mathrm{~h}$ of incubation, the SGF was replaced with SIF and masses of hydrogels were determined every 10 min during incubation for an additional period of $1 \mathrm{~h}$. Excessive medium has been carefully removed from the hydrogel surface using absorbent paper. All tests were performed in triplicate.

\section{Encapsulation efficiency (EE)}

The encapsulation efficiency (EE) of each enzyme inside the biopolymer-based $\mathrm{pH}$-sensitive hydrogels was determined by measuring the catalytic activity of each enzyme in the initial solution (pancreatin + biopolymer solutions) and the final solution (after encapsulation, the residual activities of enzymes were evaluated in an ionic medium), as shown in equation $2 .{ }^{16}$

$$
E E(\%)=\left(\frac{A_{i}-A_{f}}{A_{i}}\right) \times 100
$$

where $A_{i}$ and $A_{f}$ are the hydrolytic activity of each enzyme at initial time and after the encapsulation procedure (residual ionic solutions), respectively. 


\section{Determination of hydrolytic activities}

\section{$\alpha$-Amylase activity}

$\alpha$-Amylase activity was determined according to a methodology described by Miller ${ }^{17}$ with slight modifications. Hydrolysis reactions were performed in $50 \mathrm{mmol} \mathrm{L}{ }^{-1}$ Tris- $\mathrm{HCl}$ buffer at $\mathrm{pH} 7.0$ and $37^{\circ} \mathrm{C}$ under agitation in an orbital shaker using $1 \%\left(\mathrm{~m} \mathrm{v}^{-1}\right)$ starch solution as substrate. The obtained glucose concentration was measured by recording absorbance at $550 \mathrm{~nm}$ (experiments were performed in triplicate). The standard glucose curve ranging from 1.85 to $22.20 \mu \mathrm{mol} \mathrm{mL}^{-1}$ was also developed using the same procedure. An international unit of $\alpha$-amylase activity (U) was defined as the enzyme mass required to release $1 \mu \mathrm{mol}$ of glucose per minute of reaction under the experimental conditions described above.

\section{Lipase activity (LA)}

Lipase activity was assessed through olive oil emulsion hydrolysis ${ }^{18}$ with minor modifications. In standard conditions, the reaction mixture was composed of $1.25 \mathrm{~g}$ of olive oil, $3.75 \mathrm{~g}$ of an arabic gum solution at $3 \%\left(\mathrm{~m} \mathrm{v}^{-1}\right)$ and $5 \mathrm{~mL}$ of $100 \mathrm{mmol} \mathrm{L}^{-1}$ sodium phosphate buffer at $\mathrm{pH}$ 8.0. The emulsion was placed in a $125 \mathrm{~mL}$ conical flask and incubated in a water bath shaker at controlled temperature $\left(37^{\circ} \mathrm{C}\right.$ ) under continuous agitation at $200 \mathrm{rpm}$ for $5 \mathrm{~min}$. Then, $10 \mathrm{~mL}$ of an ethanol solution at $95 \%\left(\mathrm{~m} \mathrm{~m}^{-1}\right)$ was added to the mixture and titrated with a $30 \mathrm{mmol} \mathrm{L}^{-1} \mathrm{NaOH}$ solution using phenolphthalein as indicator. The control assay was performed in the absence of an enzyme. An international unit of lipase activity (U) was defined as the mass of enzyme required to release $1 \mu \mathrm{mol}$ of free fatty acid per minute of reaction. All assays were performed in triplicate.

\section{Protease activity (PA)}

The test performed to determine protease activity was based on a methodology employed by Charney and Tomarelli, ${ }^{19}$ but with a few adaptations. Hydrolysis was performed at $50 \mathrm{mmol} \mathrm{L}^{-1}$ Tris- $\mathrm{HCl}$ buffer at $\mathrm{pH} 7.5$ and $37{ }^{\circ} \mathrm{C}$ for $15 \mathrm{~min}$. The reaction was stopped by adding $1.60 \mathrm{~mL}$ of $20 \%\left(\mathrm{~m} \mathrm{v}^{-1}\right)$ trichloroacetic acid, followed by centrifugation at $4000 \mathrm{rpm}$ for $30 \mathrm{~min}$. Supernatants were collected for a spectrophotometric analysis at $400 \mathrm{~nm}$. In this set of experiments, an analytical curve at protease concentrations ranging from 5 to $90 \mathrm{U} \mathrm{mL}^{-1}$ was also performed under similar conditions. One unit of proteolytic activity (U) was defined as the mass of enzyme required to hydrolyze $1 \mathrm{mg}$ of azocasein per minute of reaction. These analyses were also performed in triplicate.

\section{Pancreatin release studies}

The release of pancreatin encapsulated in different biopolymers was carried out using a methodology described by Dini et al. ${ }^{15}$ with some modifications. Thereunto, $200 \mathrm{mg}$ of hydrogels were placed in $100 \mathrm{~mL}$ of SGF at $37{ }^{\circ} \mathrm{C}$ and $200 \mathrm{rpm}$. Aliquots (2 mL) were collected at 15, 30, 60, 90 and $120 \mathrm{~min}$. After two hours in an SGF, hydrogels were removed and monitored for another hour in a SIF, but now aliquots were collected every $10 \mathrm{~min}$. Each collected aliquot had their medium replaced and the activity of enzymes was analyzed. Pancreatin release of a commercial formulation (200 mg of material) was also evaluated following the same procedures as the ones used for hydrogels. All tests were performed in triplicate.

\section{Results and Discussion}

\section{Hydrogels characterization}

\section{Thermogravimetric analysis (TGA)}

There are two stages of degradation of alginate hydrogel (AH) beads: water loss, followed by sodium carbonate formation (as an intermediate product generated by decomposing alginate carbon chains). ${ }^{20}$ Data showed mass losses of around $10.6 \%$ with temperatures ranging from 70 to $133{ }^{\circ} \mathrm{C}$ and $36.6 \%$ at around $253{ }^{\circ} \mathrm{C}$. Loaded and control AH exhibited a very similar profile (Figure 1a). The TG residue presented approximately $50 \%$ of initial mass (similar for both alginate hydrogels) after the heating cycle. Control carrageenan hydrogel $(\mathrm{CH})$ presented only one thermal event with mass loss of around $25.5 \%$ (194 to $250{ }^{\circ} \mathrm{C}$ ) which corresponds to the $\kappa$-carrageenan decomposition, while there was approximately $60 \%$ of initial mass after the heating cycle. ${ }^{21}$ On the other hand, loaded $\mathrm{CH}$ exhibited three mass losses: around 32.2, 4.8 and $7.3 \%$ (150 to $202{ }^{\circ} \mathrm{C}, 206$ to $258{ }^{\circ} \mathrm{C}$ and 264 to $348{ }^{\circ} \mathrm{C}$, respectively) (Figure $1 \mathrm{~b}$ ). The residue found after the heating cycle corresponded to approximately $52.5 \%$ of initial mass, thus resulting in less stability for the loaded carrageenan hydrogel. It might have occurred due to the fact that carrageenan hydrogels present higher encapsulation efficiency for enzymes, which leads to a decrease in thermal stability with rising temperatures. At temperatures higher than $100^{\circ} \mathrm{C}$, a variety of irreversible and degradative reactions occur in enzymes, thereby disrupting the covalent structure. Some of these lead to hydrolysis and deamidation of peptide bonds. The control pectin hydrogel $(\mathrm{PH})$ also exhibited mass loss of only around $40 \%$ at temperatures between 150 and $300{ }^{\circ} \mathrm{C}$, which is similar to that found by Cui et al., ${ }^{22}$ while the loaded $\mathrm{PH}$ presented two mass losses, one at around $8 \%$ 
(150 to $188{ }^{\circ} \mathrm{C}$ ) and the other at $29 \%\left(190\right.$ to $\left.300{ }^{\circ} \mathrm{C}\right)$ (Figure 1c). Thence, the loaded pectin hydrogel presented the greatest thermal stability. On the other hand, pectin hydrogel presented less thermal stability when compared with other hydrogels, since $35 \%$ of mass was found after the thermogravimetric analysis. Percentage mass loss data at standardized temperature between 40 to $500{ }^{\circ} \mathrm{C}$, obtained by TG curves (Figure 1) have been shown in the Supplementary Information section.
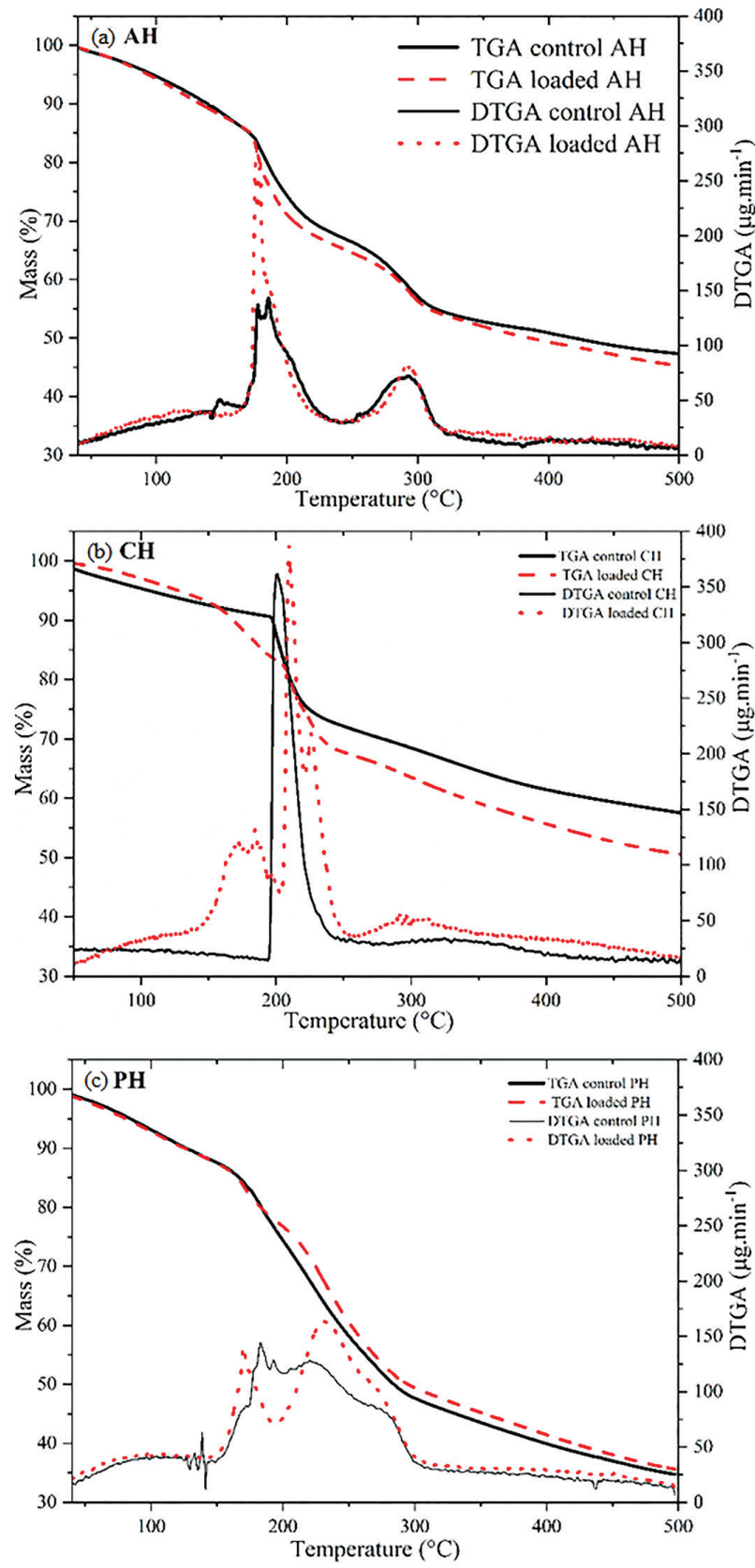

Figure 1. TGA and DTGA of control and loaded hydrogels: (a) alginate $(\mathrm{AH})$; (b) carrageenan $(\mathrm{CH})$ and $(\mathrm{c})$ pectin $(\mathrm{PH})$. The control corresponds to the unloaded hydrogels.

\section{Fourier transform infrared spectroscopy (FTIR)}

Both the control and respective loaded hydrogel beads presented a similar absorption profile: the bands exhibited discrete enlargements and displacements, which reaffirmed that enzymes are located within the formed polymeric matrices, regardless of the polymer being employed (see Figure 2 and Table 1).

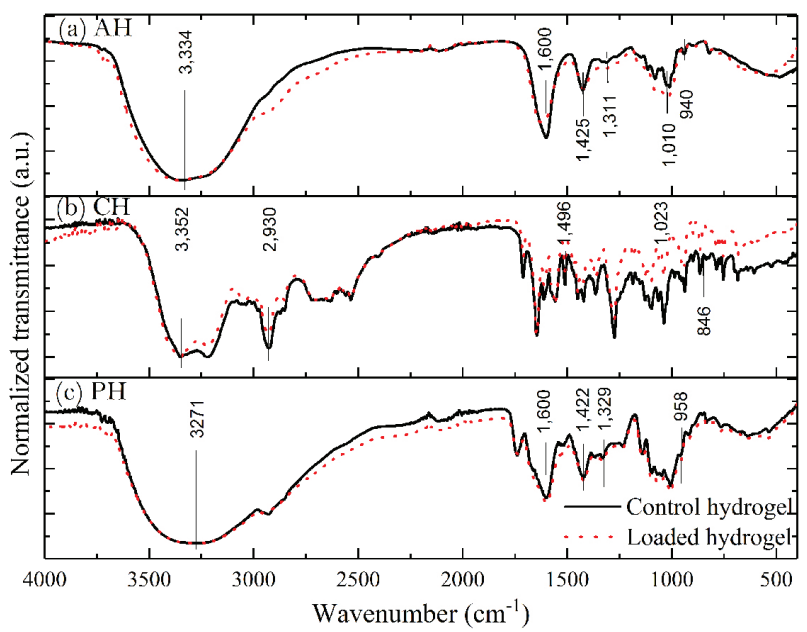

Figure 2. FTIR (ATR) spectra of control and loaded hydrogel: (a) alginate $(\mathrm{AH})$; (b) carrageenan $(\mathrm{CH})$ and $(\mathrm{c})$ pectin $(\mathrm{PH})$.

Bands of around 1,425 and 1,600 $\mathrm{cm}^{-1}$ were assigned to asymmetric and symmetric stretching vibrations of carboxylic acid groups in alginate and pectin, respectively, which were also found in other hydrogel beads prepared by using these materials. The broad band in the region ranging from 3,500 to $3,100 \mathrm{~cm}^{-1}$ observed for all hydrogels was attributed to $\mathrm{OH}$ stretching. ${ }^{23}$ According to Elsupikhe et al., ${ }^{24}$ the absorption observed at $1,496 \mathrm{~cm}^{-1}$ is characteristic of sulfate stretch, while the absorption at $847 \mathrm{~cm}^{-1}$ was assigned to $\mathrm{C}-\mathrm{O}-\mathrm{S}$ axial secondary sulfate on the C-4 of galactose. ${ }^{24}$

\section{Scanning electron microscopy (SEM)}

The air-dried hydrogels morphology of alginate, $\kappa$-carrageenan and pectin loaded with pancreatin can be observed in Figure 3. Based on an image analysis through the Image ${ }^{\mathrm{TM}}$ software, ${ }^{13}$ hydrogels spheres of alginate, $\kappa$-carrageenan and pectin hydrogels presented diameters of approximately $1.23,0.89$ and $1.19 \mathrm{~mm}$, respectively. These sizes were expected (around $1 \mathrm{~mm}$ ) for large microparticles such as hydrogel beads. ${ }^{9}$ Alginate hydrogel beads presented spherical shape, while the other hydrogels presented distorted spherical forms with some wrinkles on their surface which has been caused by the air-drying process that promotes strong deformation and, consequently, an irregular surface. ${ }^{25}$ The folds and creases on their surface, 
Table 1. FTIR data of control and loaded hydrogel of alginate $(\mathrm{AH})$, carrageenan $(\mathrm{CH})$ and pectin $(\mathrm{PH})$

\begin{tabular}{|c|c|c|c|c|c|c|}
\hline & \multicolumn{6}{|c|}{ Wavenumber $/ \mathrm{cm}^{-1}$} \\
\hline & \multicolumn{2}{|c|}{$\mathrm{AH}^{\mathrm{a}}$} & \multicolumn{2}{|c|}{$\mathrm{CH}^{\mathrm{a}}$} & \multicolumn{2}{|c|}{$\mathrm{PH}^{\mathrm{a}}$} \\
\hline & Control & Loaded & Control & Loaded & Control & Loaded \\
\hline OH stretching & 3,334 & 3,354 & 3,352 & 3,352 & 3,271 & 3,271 \\
\hline \multirow[t]{2}{*}{$\mathrm{COO}^{-}$stretching } & 1,$600 ; 1,425$ & 1,$621 ; 1,417$ & $--^{\mathrm{a}}$ & $--^{\mathrm{a}}$ & 1,$600 ; 1,422$ & 1,$598 ; 1,421$ \\
\hline & 1,311 & 1,311 & & & 1,329 & 1,330 \\
\hline $\mathrm{C}-\mathrm{O}$ stretching & 940 & 940 & 1,$023 ; 1,031$ & 918 & 958 & 960 \\
\hline $\mathrm{C}-\mathrm{O}-\mathrm{S}$ axial & $--^{\mathrm{a}}$ & $--^{\mathrm{a}}$ & 846 & 844 & $--^{\mathrm{a}}$ & $--^{\mathrm{a}}$ \\
\hline Sulfate stretch & $-{ }^{\mathrm{a}}$ & $--^{\mathrm{a}}$ & $908 ; 906$ & 1,496 & $--^{\mathrm{a}}$ & $--^{\mathrm{a}}$ \\
\hline $\mathrm{C}-\mathrm{C}$ stretch & 1,$010 ; 890$ & 1,$023 ; 891$ & - & - & $--^{\mathrm{a}}$ & $-{ }^{\mathrm{a}}$ \\
\hline $\mathrm{C}-\mathrm{H}$ stretch & $-{ }^{\mathrm{a}}$ & $-{ }^{\mathrm{a}}$ & 2,930 & 2,930 & $-{ }^{\mathrm{a}}$ & $-{ }^{\mathrm{a}}$ \\
\hline Ionic bonds & 1,$425 ; 1,417$ & 1,$425 ; 1,417$ & $-{ }^{\mathrm{a}}$ & $--^{\mathrm{a}}$ & $-{ }^{\mathrm{a}}$ & $-{ }^{\mathrm{a}}$ \\
\hline
\end{tabular}

${ }^{\mathrm{a} B a n d}$ not detected.

mainly observed in carrageenan and pectin hydrogels (Figures $3 \mathrm{~b}$ and $3 \mathrm{c}$ ), are assigned to the swollen matrix, since a partial collapse of the three-dimensional network occurs during the drying step. ${ }^{26}$ Similar observations were also reported in other studies in which air-dried hydrogel beads were employed..$^{23,26}$

(a)
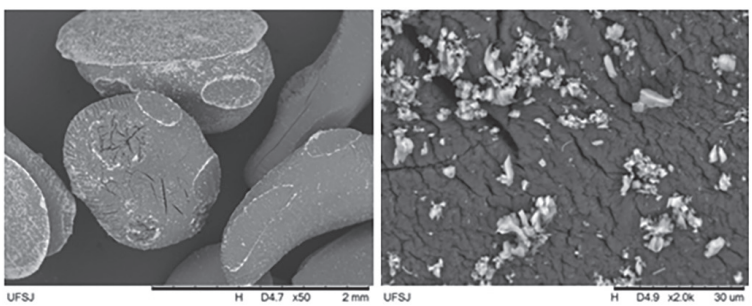

(b)
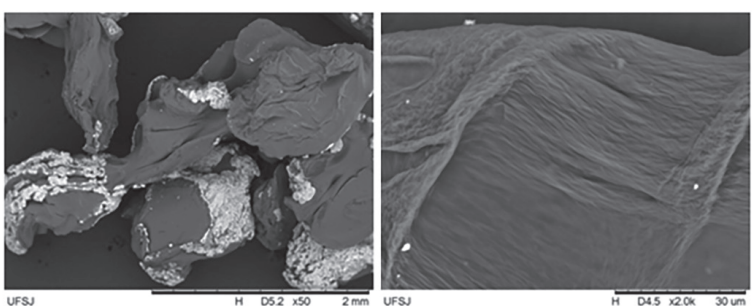

(c)
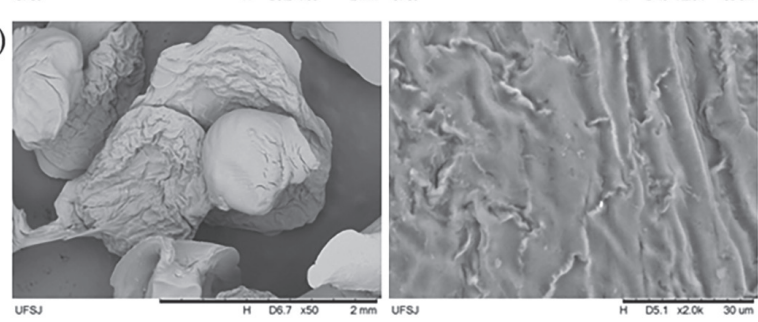

Figure 3. SEM images of air-drying hydrogels from: (a) alginate; (b) carrageenan and (c) pectin at $50 \times$ (left) and 2,000× (right) magnification, respectively.

\section{Swelling degree (SD) data}

The analysis of hydrogels SD (Table 2) aimed to evaluate the absorptive capacity of polymer matrices when submitted to mediums under different $\mathrm{pH}$ conditions. Since the present work aimed to develop a material capable of protecting pancreatin from extreme $\mathrm{pH}$ conditions, such as stomach acid, and promote its release into the intestine, it was expected that hydrogels would present a slight swelling in a simulated gastric fluid (SGF), thus contributing to a minimum deformation of matrices and, consequently, low enzymatic release. This occurs on account of carboxyl groups remaining non-ionized and keeping enzymes in the carrier structure in an acid-pH stomach. ${ }^{23,27-29}$ This was mainly due to alginate hydrogel presenting SD of around $42 \%$, while pectin and carrageenan hydrogels presented almost 3- and 5.5-fold increase in SD values, respectively. It has been reported that alginate, pectin and carrageenan hydrogels varies as a function of $\mathrm{pH}$ variations, so that there is low swelling of matrices in gastric $\mathrm{pH}$ conditions, thence causing low release of enzymes due to a change from - $\mathrm{COO}-$ to $-\mathrm{COOH}$ for alginate and pectin, and from $-\mathrm{OSO}_{3}$ - to $-\mathrm{OSO}_{3} \mathrm{H}$ for carrageenan..$^{23,29} \mathrm{On}$ the other hand, in intestinal $\mathrm{pH}$ conditions, it was desirable to achieve as much swelling as possible, which implies in maximum deformation, which leads to the opening of matrices pores and, consequently, releasing enzymes. This is due to the fact that these groups get ionized in alkaline or neutral media of the small intestine and the polymer swells on account of electrostatic repulsion, while enzymes are simultaneously released into the medium. ${ }^{23,29}$ This situation was observed, since alginate and pectin hydrogels presented higher SD values (1,578 and $1,781 \%$, respectively) than carrageenan hydrogel (around 5 times lower).

Chemical and mechanical properties of hydrogels are closely related to their water content. Thereby, the swelling degree was also tested in distilled water and alginate hydrogel presented higher SD values, whereas carrageenan 
Table 2. Data obtained in the swelling degree (SD) analysis $(\mathrm{n}=3)$

\begin{tabular}{|c|c|c|c|c|}
\hline & & $\mathrm{W}_{0} / \mathrm{mg}$ & $\mathrm{W}_{\mathrm{f}} / \mathrm{mg}$ & $\mathrm{SD} / \%$ \\
\hline Simulated gastric fluid (pH 1.2) (SGF) & $\begin{array}{l}\text { alginate hydrogel } \\
\text { carrageenan hydrogel } \\
\text { pectin hydrogel }\end{array}$ & $\begin{array}{l}51 \pm 2 \\
54 \pm 2 \\
52 \pm 3\end{array}$ & $\begin{array}{c}73 \pm 1 \\
182 \pm 3 \\
116 \pm 2\end{array}$ & $\begin{array}{c}43 \pm 2 \\
237 \pm 13 \\
123 \pm 15\end{array}$ \\
\hline Simulated intestinal fluid (pH 5.5) (SIF) & $\begin{array}{l}\text { alginate hydrogel } \\
\text { carrageenan hydrogel } \\
\text { pectin hydrogel }\end{array}$ & $\begin{array}{l}50 \pm 1 \\
56 \pm 1 \\
53 \pm 3\end{array}$ & $\begin{array}{l}839 \pm 1 \\
249 \pm 2 \\
997 \pm 2\end{array}$ & $\begin{array}{c}1,578 \pm 32 \\
345 \pm 12 \\
1,781 \pm 111 \\
\end{array}$ \\
\hline Distilled water (pH 7.0) & $\begin{array}{l}\text { alginate hydrogel } \\
\text { carrageenan hydrogel } \\
\text { pectin hydrogel }\end{array}$ & $\begin{array}{l}54 \pm 3 \\
53 \pm 2 \\
51 \pm 1\end{array}$ & $\begin{array}{c}1,160 \pm 10 \\
681 \pm 7 \\
630 \pm 10\end{array}$ & $\begin{array}{l}2,048 \pm 89 \\
1,185 \pm 38 \\
1,135 \pm 28\end{array}$ \\
\hline
\end{tabular}

$\mathrm{W}_{0}$ : mass of hydrogels at initial time of swelling; $\mathrm{W}_{\mathrm{f}}$ : mass of hydrogels at final time of swelling.

and pectin hydrogels achieved lower $\mathrm{SD}$ values. According to Panão et al. ${ }^{30}$ the chemical nature of polymers, such as ionic groups that cause inter-macromolecular electrostatic repulsions, is one of the main contributing factors to a high absorption affinity of water. Hydrogels containing a greater number of ionic groups presented greater capacity of water absorption. The matrix porosity also contributes to increased water-hydrogel attraction forces owing to interconnected pores. When hydrogel is immersed in water, the liquid diffuses more easily into the polymer network through them. These results indicate that among the hydrogels evaluated in this study, alginate presents more ionic groups and/or higher porosity. ${ }^{30}$ On the other hand, there are carboxylic groups in pectin hydrogels forming hydrogen bonds with monomers that reduce the network flexibility, given that a complex structure does not favor water swelling.

\section{Swelling profile analysis}

The observed swelling profile confirms the data obtained by the SD tests, which demonstrates that the alginate hydrogel presented the lowest swelling degree in an SGF when compared to other materials (Figure 4). According to $\mathrm{Vigl},{ }^{31}$ alginate presents low swelling degree at low $\mathrm{pH}$ values and becomes insoluble, thus preventing the release of enzymes at $\mathrm{pH} 1.2$ when the carboxylate group is in the acid form $\left(\mathrm{p} K_{\mathrm{a}} 4.5\right) .^{32}$ Moreover, in an acidic environment, carboxylate groups of this biopolymer localized on the bead surface are protonated and a layer of alginic acid is formed. The insolubility of alginic acid and the formation of hydrogen bonds increase the structure stability. These avoid the penetration of an additional fluid into a deeper structure of beads, thus limiting their swelling in this media. ${ }^{30}$ Pectin hydrogel was expected to present a similar behavior, since it has the same carboxylic groups (non-polar form, $\mathrm{p} K_{\mathrm{a}} 4.6$ ). ${ }^{32}$ Some studies have reported that alginate and pectin hydrogels present different behaviors due to changes in $\mathrm{pH}$ environment due to alginate comprising linear chains (without ramification) and the complex structure of pectin. ${ }^{23,33}$ Carrageenan hydrogel presented a similar behavior of pectin hydrogel in an SGF. Zhu et al. ${ }^{34}$ reported that, in acidic conditions, carrageenan groups are neutralized, consequently the electrostatic attraction between semi-ester sulfates in carrageenan are weakened $\left(\mathrm{p} K_{\mathrm{a}} 1.2\right) .^{32}$

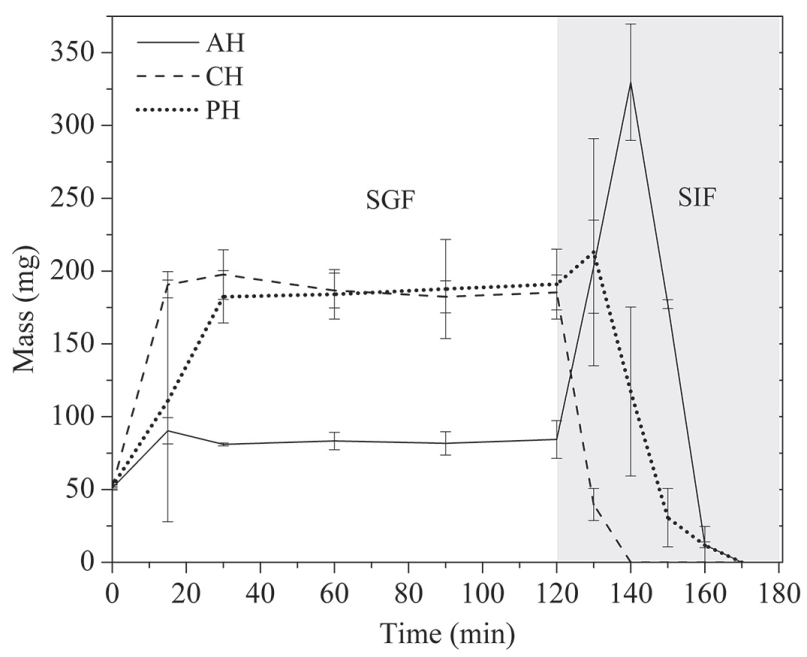

Figure 4. Swelling profile graphic $(n=3)$ of alginate hydrogel $(\mathrm{AH})$, carrageenan hydrogel $(\mathrm{CH})$ and pectin hydrogel $(\mathrm{PH})$.

Hydrogels submitted to a SIF in sequence rapidly solubilized this medium and presented smaller masses during the analysis. This is an important feature of hydrogels, since solubilization causes the dispersion of polymer matrices, which results in the release of enzymes. Alginate hydrogel also presented the highest swelling degree in a SIF and solubilization began after $20 \mathrm{~min}$. On the other hand, pectin hydrogel presented a slight swelling and the solubilization process started after $10 \mathrm{~min}$ in a SIF, while carrageenan hydrogel immediately solubilized in this medium. These results suggest that the evaluated hydrogels become soluble and viscous after crossing the gastrointestinal tract, thence allowing the release of 
enzymes. ${ }^{30,31}$ The ionization degree of carboxylate residues depends on external $\mathrm{pH}$ conditions so that, at slightly higher $\mathrm{pH}$ values, the carboxylate residue remains in an anionic form with alginate and pectin hydrogels. ${ }^{28-31}$ Carrageenan hydrogel solubilized faster than the other hydrogels. In this case, the ionization degree of sulfate residues resulting in negatively charged numbers increases and sulfate electrostatic repulsion becomes prevailing. These negatively charged groups are repelled by each other, thus creating larger spaces in networks so that more water can penetrate. $^{23}$

\section{Encapsulation efficiency (EE)}

Literature emphasizes the presence of three main enzymes in pancreatin $(\alpha \text {-amylase, lipase and protease })^{1}$ through studies conducted with the aim of determining the catalytic activity of each enzyme whose data is available in Table 3. An analytical curve was designed for testing $\alpha$-amylase (ranging from 1.85 to $22.20 \mu \mathrm{mol} \mathrm{mL}^{-1}$ ) whose limit of detection (LOD) and limit of quantification (LOQ) were 0.08 and $0.25 \mu \mathrm{mol} \mathrm{mL} \mathrm{m}^{-1}$, respectively. The catalytic activity of the initial enzymatic solution was approximately $230 \mathrm{U}$, which may be attributed to the low solubility of $\alpha$-amylase in the Tris/ $\mathrm{HCl}$ buffer, or some factor that might have led to great loss of activity. A low availability of $\alpha$-amylase in the system resulted in a low encapsulation level and low EE. By considering the values obtained for all hydrogels, alginate hydrogel presented higher $\alpha$-amylase EE when compared to the others, being 1.5 and 2.3 times higher than that obtained by carrageenan and pectin hydrogels, respectively.

An analytical curve was constructed for testing protease (ranging from 5 to $90 \mathrm{U} \mathrm{mL}^{-1}$, LOD $0.12 \mathrm{U} \mathrm{mL}^{-1}$ and LOQ $0.35 \mathrm{U} \mathrm{mL}^{-1}$ ), which was the best available enzyme when compared to the others due to presenting almost 39,000 U. By taking the obtained EE values into account, carrageenan hydrogel presented the highest protease encapsulation, followed by alginate ( 1.5 times lower) and pectin hydrogels (4.3 times lower).
The lipase activity test has revealed that enzymatic availability in the solution was around 1,300 U. Considering EE data (Table 3), alginate hydrogel achieved the highest lipase encapsulation, followed by carrageenan (2.5 times lower) and pectin (6 times lower). Pectin hydrogel was the worst material to encapsulate pancreatin, probably on account of presenting a more complex structure than alginate hydrogel, which hampers the enzymes-polymer interaction and, consequently, encapsulation efficiency.

\section{Pancreatin release studies}

Studies on pancreatin release by hydrogels were performed based on the methodologies used to evaluate the enteric bioavailability of coating drugs. The $\mathrm{pH} 5.5$ was chosen for this analysis according to Aloulou et al. ${ }^{35}$ and Venkatwsh et al. ${ }^{36}$ who had indicated this value as ideal for pancreatin release in the duodenum by considering special conditions presented by patients with deficiency or insufficient production of these enzymes. Pancreatin release occurred by two mechanisms: enzyme diffusion through the pores of polymer networks when swollen and solubilization of matrices. ${ }^{37}$ As regards enzyme delayed release, solubilization of polymeric chains may be the best method, since it may result in a faster and more complete release of these enzymes. Pancreatin release studies performed in different hydrogels is in agreement with the data obtained from the swelling profile analysis.

The anionic polymers work as ion exchange resins that maintain a constant $\mathrm{pH}$ value within the polymeric network for a certain period, given that they work as buffers and are capable to maintain $\mathrm{pH}$ close to 7.0 and contribute to increase the encapsulated enzymes stability, thus preventing their denaturation or enzymatic degradation dependent on pH. ${ }^{38}$

Alginate hydrogel presented low release (76 U), as observed for $\alpha$-amylase (AR) in an SGF, which corresponds to $21 \%$ of total AR when compared to carrageenan, $128 \mathrm{U}$ (40\% of the total AR) and pectin hydrogel, i.e.; $117 \mathrm{U}$ ( $45 \%$ of the total AR). Therefore, it presented higher

Table 3. Catalytic activity and encapsulation efficiency (EE) data of $\alpha$-amylase, lipase and protease $(n=3)$ obtained from the preparation of different hydrogels

\begin{tabular}{|c|c|c|c|c|c|c|c|}
\hline & \multirow{2}{*}{ Solution } & \multicolumn{2}{|c|}{$\alpha$-Amylase } & \multicolumn{2}{|c|}{ Lipase } & \multicolumn{2}{|c|}{ Protease } \\
\hline & & Activity / U & $\mathrm{EE} / \%$ & Activity / U & $\mathrm{EE} / \%$ & Activity / U & $\mathrm{EE} / \%$ \\
\hline \multirow{2}{*}{ Alginate hydrogel } & initial & $232.2 \pm 0.3$ & \multirow{2}{*}{$18 \pm 1$} & $1,308 \pm 5$ & \multirow{2}{*}{$68 \pm 1$} & $38,870 \pm 240$ & \multirow{2}{*}{$53 \pm 0$} \\
\hline & final & $190 \pm 1$ & & $418 \pm 15$ & & $18,439 \pm 38$ & \\
\hline \multirow{2}{*}{ Carrageenan hydrogel } & initial & $232.8 \pm 0.9$ & \multirow{2}{*}{$12 \pm 0$} & $1,338 \pm 5$ & \multirow{2}{*}{$27 \pm 3$} & $38,985 \pm 352$ & \multirow{2}{*}{$78 \pm 0$} \\
\hline & final & $205.0 \pm 0.8$ & & $980 \pm 34$ & & $8,726 \pm 59$ & \\
\hline \multirow{2}{*}{ Pectin hydrogel } & initial & $234 \pm 1$ & \multirow{2}{*}{$8 \pm 1$} & $1,333 \pm 5$ & \multirow{2}{*}{$11 \pm 1$} & $39,139 \pm 176$ & \multirow{2}{*}{$18 \pm 1$} \\
\hline & final & $215.2 \pm 0.3$ & & $1,189 \pm 15$ & & $32,060 \pm 291$ & \\
\hline
\end{tabular}


stability in a gastric environment than the others. In a SIF, alginate hydrogel presented a slightly higher release than carrageenan hydrogel (363 and $317 \mathrm{U}$ in $40 \mathrm{~min}$, respectively), while pectin hydrogel only released $259 \mathrm{U}$ in $50 \mathrm{~min}$ (Figure 5a). Alginate hydrogel presented greater AR than the other materials.

Furthermore, alginate hydrogel presented the lowest lipase release (LR) (152 U) in an SGF and the greatest
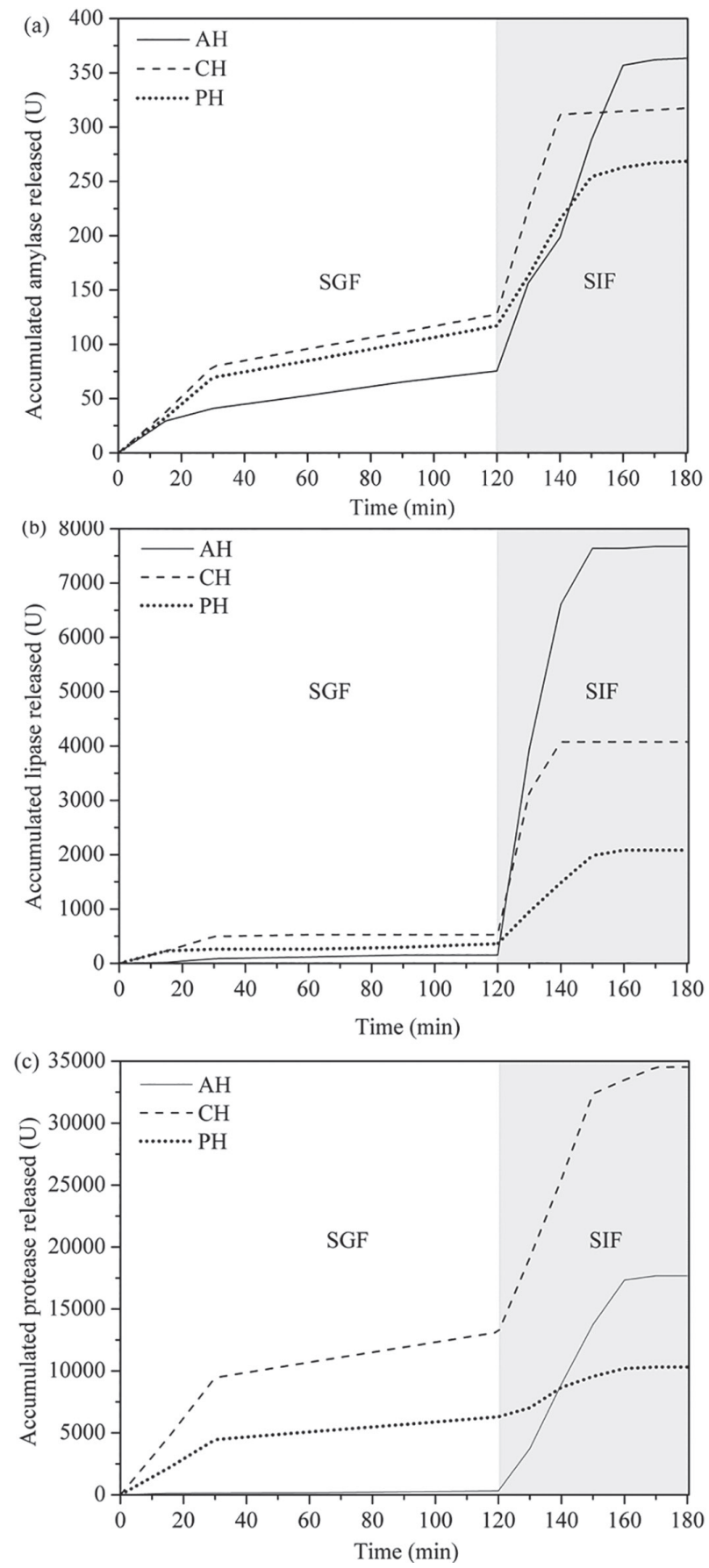

Figure 5. (a) $\alpha$-Amylase; (b) lipase and (c) protease release profile of loaded alginate hydrogel $(\mathrm{AH})$, carrageenan hydrogel $(\mathrm{CH})$ and pectin hydrogel $(\mathrm{PH})$. release (7,673 $\mathrm{U}$ at $30 \mathrm{~min})$ in a SIF. Alginate was the best hydrogel to maintain lipase activity, since it presented the highest stability in an SGF and the highest release in a SIF. Pectin hydrogel presented an enzymatic release in a gastric medium which is almost 2.5 times higher than that for alginate hydrogel ( $362 \mathrm{U}$ ), while carrageenan hydrogel released 529 U. In a SIF, carrageenan hydrogel released $4,075 \mathrm{U}$ in $20 \mathrm{~min}$ and pectin hydrogel released 2,083 $\mathrm{U}$ in $30 \mathrm{~min}$. Although LR of carrageenan was greater than that of pectin (considering total LR), carrageenan released about $12.5 \%$ of lipase, while pectin released nearly $16.5 \%$ of the amount released by alginate (Figure 5b). The higher LR observed for alginate and pectin hydrogels is in agreement with the data obtained from the EE test and swelling profile analysis.

As regards protease release (PR) in an SGF, carrageenan presented higher release $(13,135 \mathrm{U})$ when compared to alginate $(312 \mathrm{U})$ and pectin $(6,294 \mathrm{U})$ hydrogels. In this sense, it is possible to affirm that alginate hydrogel presented the greatest stability in a gastric environment. After $50 \mathrm{~min}$ in a SIF, carrageenan hydrogel also presented higher PR (34,520 U). Alginate hydrogel presented the second best release, i.e., half of the PR achieved by carrageenan hydrogel, whereas pectin hydrogel presented lower PR (less than one third) (Figure 5c). The highest PR obtained by carrageenan and alginate hydrogels confirms the data obtained from the EE test and swelling profile analysis, since carrageenan presented higher EE than alginate hydrogel. However, both hydrogels obtained total enzyme release due to solubilization of their matrices in the presence of a SIF.

In this sense, the prepared materials not only were efficient at preserving enzymatic activities, but also activated enzymes and promoted release at propitious $\mathrm{pH}$ to obtain greater action. In literature, studies on pancreatin encapsulation by hydrogels and its release aimed at pharmaceutical application have not been found. Therefore, alginate hydrogel was selected since it provided better EE, stability in an SGF and enzymatic release in a SIF.

\section{Comparison between alginate hydrogel and $\mathrm{Creon}^{\mathrm{TM}}$}

Alginate hydrogel was selected as a basis for comparison with $\mathrm{Creon}^{\mathrm{TM}}$ (commercial formulation) because it presented optimal encapsulation efficiency of pancreatin, being less swelling, achieving less enzymatic release in a simulated gastric medium and optimal release in a simulated intestinal environment. For such a purpose, the same experimental conditions used in pancreatin release studies have been adopted towards alginate hydrogel and $\mathrm{Creon}^{\mathrm{TM}}$.

As regards $\alpha$-amylase release (Figure 6a), $\mathrm{Creon}^{\mathrm{TM}}$ presents better stability in an SGF than alginate hydrogel, 
but with lower release (44 and $76 \mathrm{U}$, respectively). However, $\alpha$-amylase activities found in a SIF were very similar (353 and $363 \mathrm{U}$, respectively). With respect of lipase release in an $\mathrm{SGF}$, both $\mathrm{AH}$ and $\mathrm{Creon}^{\mathrm{TM}}$ presented a similar behavior, but lipase release by hydrogel was thorough $(7,500 \mathrm{U}$ ) and faster (occurred in $20 \mathrm{~min}$ in SIF) (Figure 6b). Alginate hydrogel presented higher stability than Creon $^{\mathrm{TM}}$ in an SGF regarding protease release (312 and 2,906 U, respectively) (Figure 6c). In a SIF, although $\mathrm{Creon}^{\mathrm{TM}}$
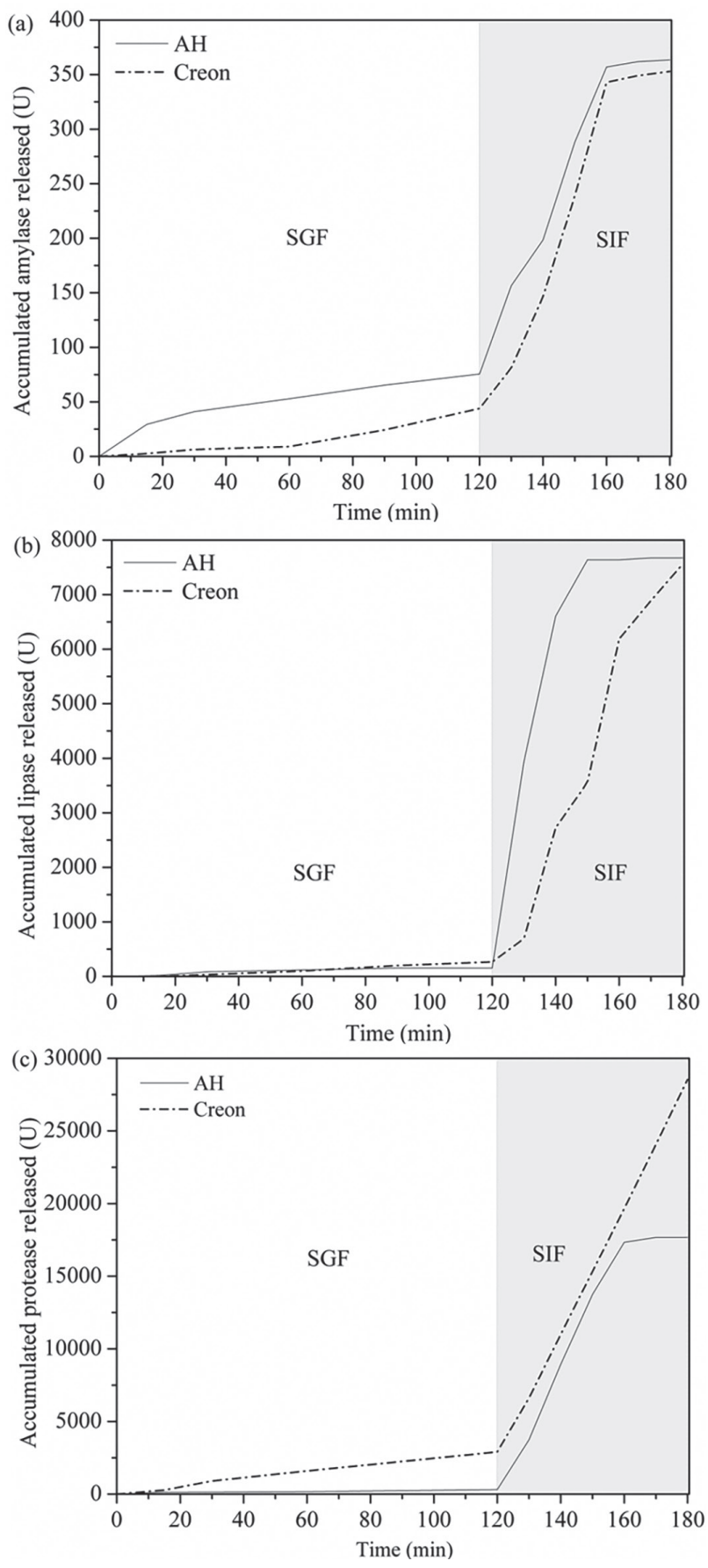

Figure 6. Release profile of (a) $\alpha$-amylase; (b) lipase and (c) protease from loaded alginate hydrogel $(\mathrm{AH})$ and $\mathrm{Creon}^{\mathrm{TM}}$. presented higher PR, enzyme release was not complete, probably on account of beads remaining in the medium ( $\mathrm{pH}$ 5.5). According to technical information, Creon ${ }^{\mathrm{TM}}$ 's coating solubilized at $\mathrm{pH} 6.8$, but patients who suffer from pancreatic disorders presented reduced bicarbonate release in their organism, which leads to a delayed release of protease ${ }^{39}$ Consequently, protein hydrolysis is inefficient due to lower contact of proteases with chyme.

Another topic that is worth discussing concerns calcium cytotoxicity. Alginate hydrogels are unstable since beads solubilize during the delayed release test in a simulated intestinal fluid. Therefore, the calcium content available in the medium is $17 \mathrm{mg}$ per $200 \mathrm{mg}$ of hydrogel. By considering the maximum tolerable dose of lipase informed by the commercial formulation $(100,000 \mathrm{U}$ a day), around $220 \mathrm{mg}$ of calcium would be ingested if alginate hydrogel was used. This is below $25 \%$ of the minimum daily calcium requirements $(1,000 \mathrm{mg}$ a day).

\section{Conclusions}

This work provides a good example of hydrogels which are able to incorporate multiple bioactive components, thus presenting new functionalities and applications. The encapsulation of enzymes by hydrogels is efficient at preserving pancreatin activity in a gastric environment and, if compared to Creon ${ }^{\mathrm{TM}}$, they provide greater and faster delayed release whose $\mathrm{pH}$ is similar to that of duodenum. In this sense, the use of natural polymers deserves more attention, since they increase the stability of biopharmaceuticals. Moreover, the preparation of beads is simple and inexpensive if compared to the coating process, which requires several excipients that may increase interactions between excipient-excipient and excipient-biopharmaceutical. As regards the hydrogels produced through the present study, alginate is considered an appropriate alternative to replace the commercial formulation containing pancreatin, since it presented better results, mainly with respect to lipase.

\section{Supplementary Information}

Supplementary information is available free of charge at http://jbcs.sbq.org.br as PDF file.

\section{Acknowledgments}

This study was financed in part by the Coordenação de Aperfeiçoamento de Pessoal de Nível Superior, Brasil (CAPES), Finance Code 001, and FAPEMIG (process APQ-02245-15). The authors thank CPKelco for the pectin 
donation and Prof Keyller Bastos Borges for conducting the SEM analysis in the facilities of the Federal University of São João del Rei (UFSJ).

\section{References}

1. Wallace, J. L.; Sharkey, K. A. In Goodman \& Gilman's Pharmacological Basis of Therapeutics; Brunton, L. L. ed.; McGraw-Hill: New York, USA, 2011, ch. 45.

2. Fieker, A.; Philpott, J.; Armand, M.; Clin. Exp. Gastroenterol. 2011, 4, 55.

3. Zhang, A.; Chen, F.; Zhang, R.; Deng, Z.; McClements, D. J.; J. Agric. Food Chem. 2016, 64, 9616.

4. Tabernero, A.; González-Garcinuño, A.; Del Valle, E. M. M.; Galán, M. A.; Rev. Chem. Eng. 2016, 32, 507.

5. Devi, N.; Sarmah, M.; Khatun, B.; Maji, T. K.; Adv. Colloid Interface Sci. 2017, 239, 136.

6. Liu, A. L.; Garcia, A. J.; Ann. Biomed. Eng. 2016, 44, 1946.

7. Gyles, D. A.; Castro, L. D.; Silva Jr., J. O. C.; Riberio-Costa, R. M.; Eur. Polym. J. 2017, 88, 373.

8. McClements, D. J.; Adv. Colloid Interface Sci. 2017, 240, 31.

9. McClements, D. J.; Adv. Colloid Interface Sci. 2018, 253, 1.

10. Cao, J.; Li, Q. In Encyclopedia of Food Security and Sustainability, vol. 2; Ferranti, P.; Berry, E. M.; Anderson, J. R., eds.; Elsevier Inc.: New York, USA, 2019.

11. Daniel-da-Silva, A. L.; Ferreira, L.; Gil, A. M.; Trindade, T.; J. Colloid Interface Sci. 2011, 355, 512.

12. Martins, J. T.; Cerqueira, M. A.; Bourbon, A. I.; Pinheiro, A. C.; Souza, B. W. S.; Vicente, A. A.; Food Hydrocolloids 2012, $29,280$.

13. Schneider, C. A.; Rasband, W. S.; Eliceiri, K. W.; Nat. Methods 2012, 9, 671.

14. Lee, C. H.; Bae, Y. C.; Macromolecules 2015, 48, 4063.

15. Dini, C.; Islan, G. A.; Castro, G. R.; Appl. Biochem. Biotechnol. 2014, 174, 2031.

16. Correia, C.; Rijo, P.; Ascensão, L.; Nicolai, M.; Matias, D.; Reis, C. P.; Biomed. Biopharm. Res. 2014, 11, 111.

17. Miller, G. L.; Anal. Chem. 1959, 31, 426.

18. Soares, C. M. F.; Castro, H. F.; Moraes, F. F.; Zanin, M. G.; Appl. Biochem. Biotechnol. 1999, 79, 745.

19. Charney, J.; Tomarelli, R. M.; J. Biol. Chem. 1947, 171, 501.

20. Fernandes, R. S.; Moura, M. R.; Glenn, G. M.; Aouada, F. A.; J. Mol. Liq. 2018, 265, 327.

21. Sun, G.; Liang, T.; Tan, W.; Wang, L.; Food Hydrocolloids 2018, 85,61 .
22. Cui, S.; Yao, B.; Gao, M.; Sun, X.; Gou, D.; Hu, J.; Zhou, Y.; Liu, Y.; Carbohydr. Polym. 2017, 157, 766.

23. Zhou, M.; Hu, Q.; Wang, T.; Xue, J.; Luo, Y.; Int. J. Biol. Macromol. 2018, 120, 859.

24. Elsupikhe, R. F.; Shameli, K.; Ahmad, M. B.; Ibrahim, N. A.; Zainudin, N.; Nanoscale Res. Lett. 2015, 10, 302.

25. Jung, J.; Arnold, R. D.; Wicker, L.; Colloids Surf., B 2013, 104, 116.

26. Xing, L.; Sun, J.; Tan, H.; Yuan, G.; Li, J.; Jia, Y.; Xiong, D.; Chen, G.; Lai, J.; Ling, Z.; Chen, Y.; Niu, X.; Int. J. Biol. Macromol. 2019, 127, 340.

27. Aguilar, M. R.; Elvira, C.; Gallardo, A.; Vázquez, B.; Román, J. S. In Topics in Tissue Engineering, vol. 3; Ashammakhi, N.; Reis R.; Chiellini, E., eds.; University of Oulu: Oulu, Finland, 2007, ch. 6.

28. Xu, W.; Ling, P.; Zhang, T.; J. Drug Delivery 2013, 2013, article ID 340315.

29. Leong, K. H.; Chung, L. Y.; Noordin, M. I.; Onuki, Y.; Morishita, M.; Takayama, K.; Carbohydr. Polym. 2011, 86, 555.

30. Panão, C. O.; Campos, E. L. S.; Lima, H. H. C.; Rinaldi, A. W.; Lima-Tenório, M. K.; Tenório-Neto, E. T.; Guilherme, M. R.; Asefa, T.; Rubira, A. F.; J. Mol. Liq. 2019, 276, 204.

31. Vig1, C. In Oral Delivery of Macromolecular Drugs; Bernkop-Schnürch, A., ed.; Springer: New York, USA, 2009, ch. 8 .

32. Vleugels, L. F. W.; Ricois, S.; Voets, I. K.; Tuinier, R.; Food Hydrocolloids 2018, 81, 273.

33. Pettinelli, N.; Rodríguez-Llamazares, S.; Abella, V.; Barral, L.; Bouza, R.; Farrag, Y.; Lago, F.; Mater. Sci. Eng., C 2019, 96, 583.

34. Zhu, Y.; Bhandari, B.; Prakash, S.; Food Hydrocolloids 2018 , 84, 292.

35. Aloulou, A.; Puccinelli, D.; Sarles, J.; Laugier, R.; Leblond, Y.; Carriere, F.; Aliment. Pharmacol. Ther. 2008, 27, 283.

36. Venkatwsh, G.; Kramer, C.; Fabiani, F.; Mapelli, L.; Ortenzzi, G.; Latino, M.; US pat. 201401273072014.

37. George, M.; Abraham, T. E.; J. Controlled Release 2006, 114, 1. 38. Bernkop-Schnürch, A.; Adv. Drug Delivery Rev. 2005, 57, 1553.

39. Kopelman, H.; Corey, M.; Gaskin, K.; Durie, P.; Weizman, Z.; Forstner, G.; Gastroenterology 1988, 95, 349.

Submitted: March 25, 2019 Published online: August 6, 2019 